\title{
Use of Flipped model classroom teaching on learning of Immunology in second professional Medical Students
}

\author{
Gupta, . $^{1}$, Datta, $P .^{2}$, Gupta, $M .^{3} \&$ Singh, $M .^{4}$
}

\begin{abstract}
Objectives: Over time medical para-clinical subject teachers have felt that undergraduate students have difficulty in understanding immunological concepts of infections. The objectives of the study were to compare the effectiveness of traditional method of teaching with the flipped classroom teaching (FCT) model in Immunology and to assess the perception of students towards the flipped classroom teaching (FCT) model using semi-structured feedback.

Methodology: In the study, the flipped classroom model was employed. This is a single centre study involving 100 students of second year MBBS where the students were required to learn and understand the supplied material before coming to the class. During the class, clinically applied aspects of Immunology topic including higher levels were discussed. Ten sessions were done on FCT. Pre class and post class student's knowledge of concept was assessed using MCQs on the given session. Also a theory test was conducted on the same topic at the end of completion of the Immunology topic and comparison was done with a topic in which teaching was done based on didactic lectures only. Feedback was taken from the students in the peer validated questionnaire provided having open ended question also. Similar feedback was taken from participating teachers.
\end{abstract}

Results: The MCQ marks were categorized in three groups; students scoring $<5,6-8$ and $>8$ out of 10 . In the post class assessment significantly higher proportion of students secured score between $9-10$ $(\mathrm{P}<0.001)$. Overall scores of students was also significantly higher in post class assessment. However, summative assessment done by Theory test (having long answer questions and short answer questions) showed no statistical difference $(P>0.10)$. Regarding feedback from the students; a positive attitude was seen for incorporating the flipped class teaching as assessment method showing a significant value $(\mathrm{p}=0.005)$. In terms of duration for the flipped class study, students disagreed that FCT takes longer time than routine lecture. Feedback from the teachers showed that this is a good method of teaching regards to some difficult topics but some preparation is required beforehand.

Conclusions: There was a positive feedback by the students towards flipped classroom teaching method as understanding of the topics covered was much more. According to the assessment, Flipped teaching approach offered no additional benefits as compared to non-flipped traditional method.

Key words: Medical education, Flipped classroom teaching, Immunology, Medical students

\section{Introduction}

Although the flipped or inverted classroom has been in existence for many years, this modality is relatively new to undergraduate medical education.

\footnotetext{
${ }^{1}$ Professor, Department of Microbiology, Govt. Medical \& Hospital, Sector 32, Chandigarh.

${ }^{2}$ Assistant Professor, Department of Microbiology, Govt. Medical \& Hospital, Sector 32, Chandigarh.

${ }^{3 \& 4}$ Demonstrator, Department of Microbiology, Govt.

Medical \& Hospital, Sector 32, Chandigarh.

Corresponding Author

Dr. Varsha Gupta

Department of Microbiology, Govt Medical College

Hospital, Sector 32-B, Chandigarh, India 160030.

E-mail:varshagupta_99@yahoo.com
}

The first documented use of the Flipped Classroom teaching (FCT) in teaching medical students was only recently published (Prober, 2012). In terms of Bloom's revised taxonomy, the traditional lecture promotes lower level cognitive skills (gain and comprehension of factual knowledge), whereas the FCT offers the opportunity for the students to engage in higher order cognition (application, analysis, evaluation, and synthesis of knowledge) (Brame, 2013).

Traditional teaching, at present is being replaced by the interactive learning methodology. It is considered to be student

DOI: http://doi.org/10.4038/seajme.v13i1.61

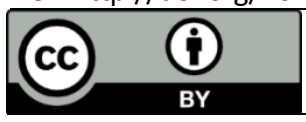

(C) SEAJME. This is an Open Access article distributed under the terms of the Creative Commons Attribution

License (http://creativecommons.org/licenses/by/4.0/), which permits unrestricted use, distribution, and reproduction in any medium, provided the original author and source are credited 
centered and involves students actively to improve learning. The flipped teaching is a reversal of the conventional classroom teaching where the materials for the particular topic are provided to the students beforehand and they go through it and come prepared with the topic in the class prior to the scheduled lecture time. During the class hour, the topic is discussed using active teaching methods to fill in knowledge gaps and the concept is made clear to the students (Bergmann \& Sams, 2012; Singh et al., 2018).

This way of learning is beneficial in many aspects. As teachers have limited time in the class to focus on individual student, clarify their doubts and build depth of knowledge, the flipped class of learning can act as beneficial tool to approach students. On comparing with a traditional 'chalk and talk', this mode of learning will increase the valuable time available for teachers to work directly with students during class (Lage et al., 2000). Apart from this, students can coordinate in a small group and discuss their queries with each other as well as increase opportunities and time for students to engage in more peer-to-peer work.

Furthermore, in today's times, there is an easy access to the internet by everyone through which the method of flipping class becomes more interactive. This is one of the methods to stimulate self-directed learning in students in the way of engaging themselves and enhancing the learning process (Herbert et al., 2017). This approach utilizes the increasing availability of digital technology to create learning resources that can be accessed prior to attending class, with face-to-face sessions then becoming more student-centered via discussion, collaborative learning and problem-solving activities (Pickering \& Roberts, 2018). Plethora of the world's leading universities has applied this model of teaching in their classroom and the performance and perception of the flipped classroom model has been studied in several student cohorts (Mclaughlin, 2014).

Despite the interest of many trainers in the flipped classroom model, there are few studies reported in literature of health sciences identifies few studies that detail the flipped classroom designs and report their effect on course outcomes with an outcome of mixed results in student performance and satisfaction (Critz et al., 2013; Missildineet et al., 2013; Schlairet et al., 2014; Ratta et al., 2015).

Previous study showed that a flipped classroom based on an automated tutoring system had subsequent issues with grasping of concepts (Strayer et al., 2012). In another study (Martin et al., 2013) it was concluded that a flipped classroom using applications to highlight teaching points had no difference in effectiveness from a conventional classroom teaching. However, there have been few studies appraising the practicability of the medical students to the flipped classroom learning. Thus, a study was conducted to assess the perception of second year undergraduate medical students to an interactive session on Immunology by implementing the flipped classroom approach.

\section{Aims}

To evaluate the perception of second year undergraduate medical students to an interactive session on Immunology topic by implementing the flipped classroom approach in ten lectures.

\section{Objectives}

- Comparison of effectiveness of traditional method of teaching with the flipped model classroom teaching.

- To assess the perception of students towards the Flipped Model Learning using semi-structured peer validated feedback questionnaire.

\section{Methodology}

This was a single-center study conducted in second year undergraduate medical students in the Department of Microbiology, Government Medical College and Hospital -32, Chandigarh. The study was approved by the Institutional Ethics Committee and written informed consent was obtained from the students before enrolling them in the study. Routinely for teaching undergraduate second year students, didactic lectures are given. Immunology is taught as one of the topic in the subject of Microbiology and about ten lectures are taken per batch of students. In the present study conducted over a period of two months (Feb-Mar 2018), the flipped classroom model was employed. Firstly sensitization of both the students as well as teachers regarding what is flipped classroom teaching and how we are going to implement it for Immunology topic was done.

A Whatsapp group was made that included all the 100 students of the class of second year MBBS. Out of these 10 student coordinators volunteered to lead their teams in pre classroom learning. Further each coordinator 
interacted with ten students of the batch. So total of 100 students were enrolled.

All the five teachers participated in the preparation of ten lectures on Immunology and finalization of the content of each lecture. This content was circulated by e mails of all the students at least two days before each lecture for which student class coordinators were involved. It was confirmed on Whatsapp group that all of them participated in the study and got the pre-class lecture/material. They were asked to come prepared before attending didactic lecture on the same topic as per rosters. During the class, the teachers discussed the same topic including some clinically applied aspects of Immunology.

For assessment, MCQs were prepared by the faculty teaching staff and post graduate students were involved in validation of these MCQs using Item analysis (Kashyap, 2015). A total of ten MCQ's were given with a score of 10 marks for each right question. Before starting the lecture the student's knowledge of concept was assessed using MCQs on the given topic.
Then a didactic lecture on the same topic was conducted by the teacher and at the end of the lecture again the assessment was done based on same MCQs as given before the start of the lecture. A total of ten lectures were completed in the similar manner following FCT covering whole of the topic of Immunology.

On the completion of the topic, summative assessment was done by theory test in Immunology which had long answer questions and short answer questions. The marks obtained in the Immunology Theory test were compared with the test done in Parasitology where Flipped classroom model of teaching was not used and rather teaching was done based on didactic lectures only.

After the completion of this whole exercise of FCT a peer validated feedback questionnaire (5 point Likert scale was used having open ended question) was circulated amongst students and teachers and a qualitative analysis of their viewpoint was done based on their feedback (Table 1).

Table 1: Feedback questionnaire

\begin{tabular}{clccc}
\hline No & \multicolumn{1}{c}{ Statement } & Disagree & Neutral & Agree \\
\hline 1 & $\begin{array}{l}\text { Flipped class room teaching was a feasible } \\
\text { exercise }\end{array}$ & 0 & 0 & 5 \\
2 & $\begin{array}{l}\text { It's a satisfactory method of assessing competency } \\
\text { in students }\end{array}$ & 0 & 1 & 4 \\
$3 \quad \begin{array}{l}\text { Flipped class room teaching should be used for } \\
\text { assessing other competencies as well }\end{array}$ & 0 & 0 & 5 \\
$4 \quad$ It makes students confident & 0 & 0 & 5 \\
5 & $\quad$ It helps in improving the learning skills of students & 0 & 1 & 4 \\
6 & $\quad$ It would help in long-term learning & 0 & 0 & 5 \\
7 & $\quad$ This program should be continued & 0 & 0 & 5 \\
8 & $\begin{array}{l}\text { This assessment tool was an effective tool for } \\
\text { feedback. }\end{array}$ & 0 & & 5 \\
\hline
\end{tabular}

\section{Statistical analysis}

The data was analyzed by using SPSS version 22.0 (IBM Corp. Armonk, New York). Normal test of proportions was used for testing significance of difference between two proportions. ANOVA was used for testing significance of variability between mean scores in different scores. $\mathrm{P}<0.05$ was considered as significant level.

\section{Results}

One hundred students of second year MBBS comprising of 56 males and 44 females with the mean age of 19 years participated in the study. 
The MCQ marks obtained in the study were categorized in three groups; students scoring $<5,6-8$ and $>8$ out of 10 for both pre class and post class assessment. Proportion of students securing 6-8 score in pre-class assessment was significantly higher $(P<0.001)$ as compared to those in post class assessment. Whereas, in post class assessment significantly higher proportion of students secured score between $9-10(P<0.001)$. Overall scores of students was also significantly higher in post class assessment (Figure 1).

As far as comparisons of theory marks in different topics based on different teaching method i.e. comparing FCT method with routine didactic lecture teaching (Immunology vs Parasitology) no significant variability ( $P>0.10)$ was observed between scoring patterns.
All the students completed the feedback questionnaires at the end of the session, with a response rate of $100 \%$. Majority of the students felt that flipped classroom approach was a feasible exercise and it improves learning skills compared to conventional didactic teaching. A positive attitude was seen for incorporating the flipped class teaching as a teaching learning method. They also reported that their confidence and e-learning skills were improved by going through this procedure. Many students opined that more such flipped classroom sessions can be organized in the future. Many students also gave their positive response regarding use of the feedback questionnaire for evaluation. In terms of duration for the flipped class study, students disagreed that FCT takes longer time than routine lecture (Figure 1). So based on this short term evaluation it is suggested that this method enhances selfdirected learning and more clarity about the subject.

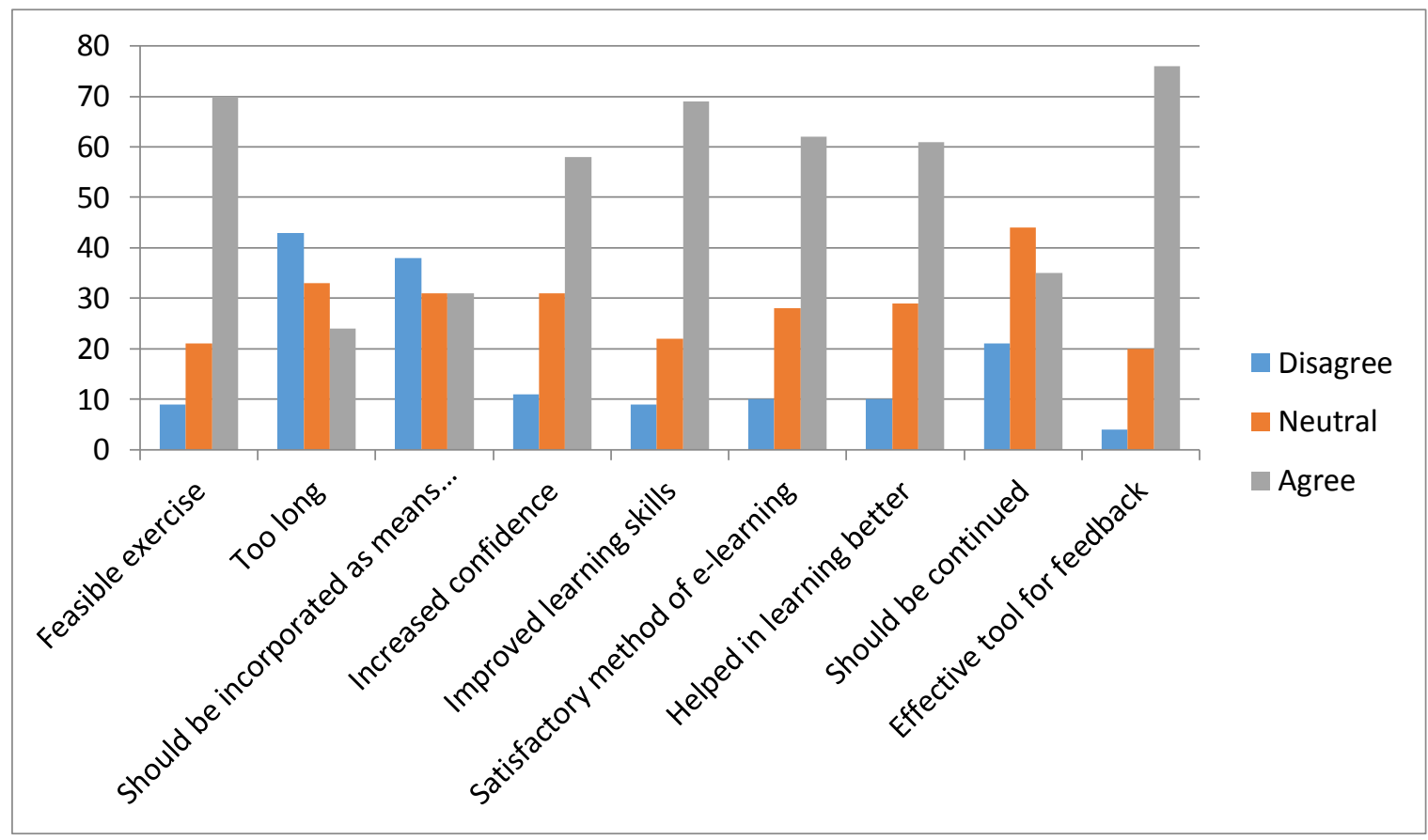

Figure 1: Graph showing Students' feedback

In our study, teachers' feedback was also taken regarding the FCT method of teaching and as per the peer validated questionnaire it was suggested that the flipped classroom teaching was more conducive for learning skills and building the confidence and thus can be preferred over traditional classroom teaching. It was a feasible method of teaching Immunology to second year medical students and should be continued. The only limitation was that some preparation is required beforehand so FCT is time consuming.

\section{Discussion}

The flipped classroom is a student-centered approach to learning that increases active learning for the student compared to traditional 
classroom-based instruction. In a study by Hamdan and others a definition has been offered: "In the flipped learning model, teachers shift direct learning out of the large group learning space and move it into the individual learning space, with the help of one of several technologies" (Hamdan et al., 2013).

A successful flipped classroom has three goals:

1. Allow the student to become critical thinker

2. Fully engage students and instructors

3. Stimulate the development of a deep understanding of the material (Mclaughlin, 2014)

The 5-E learning cycles consists of five instructional phases:

Engage, Explore, Explain, Elaborate, Evaluate

Evaluation can take the form of both formative and/or summative assessments (Jensen et al., 2015). In our study Flipped CT model was used for 2nd year BBS students to teach topic of Immunology.

The evaluation of the students was done by pre class and post class MCQs based test and at the end of the topic a theory test was taken on the topic. The results of the MCQ test show no statistical difference between the two types of teaching. However in 9-10 score, it is seen that there is difference in pre-test and post-test but since sample size is less as number of students scoring 9-10 was very less so Mann-Whitney test of comparison was used which was found to be non-significant. Further even summative assessment in the form of theory test also shows no statistical difference. In some studies students have found FCT to be relatively superior to the traditional lecture approach (Strayer, 2012; Deslauriers \& Weiman, 2011; Michaud-sacks et al., 2014. Whereas, in others students have reported lower levels of satisfaction and achievement (Persky \& Dupuis, 2014; Wong et al., 2014). However, these findings are usually based on examination score which are used as measure for learning.

A study done in the subject of Immunology shows that there was increased student satisfaction with small group activities, but no impact on examination performance (Evans, 2016). As FCT method is technology related in which all students may not have understood the topic just by slides of power point presentations. This has been highlighted in another study as well (Strayer, 2012).
Further another problem that the students encountered was that they feel that pre class learning tools should be properly aligned with the subsequent in class learning objectives in regards to detail, difficulty and relevance and the students also felt that the subject matter was overly complex to be read without faculty support (Lew, 2016).

So based on the findings by qualitative analysis of the feedback and response in open ended questions it is hypothesized that the students felt that FCT is a very good form of teaching as they gain confidence, e learning is involved in FCT and learning skills are improved so they wanted this method to be continued. However, this method was introduced for the first time in second year students, so there may be some teething problems.

FCT effectiveness lies in the fact that it promotes higher order thinking, learning and mastery of the subject matter on a consistent basis and throughout the course when compared to a traditional lecture format. In a traditional lecture, students usually have the tendency to study more heavily just prior to the midterm and final examinations.

Not many studies regarding FCT have evaluated the teachers' feedback, in our study we involved five faculty members of our department and were able to take their feedback. So based on the findings by qualitative analysis of the feedback and response in open ended questions it can be said that teachers also were of the opinion that there is more student involvement and participation in this type of teaching method. However the teachers felt since time investment is required to give optimal content of learning to students well in advance before the class, the teachers felt that it is relatively a lengthy process as compared to traditional lecture. Further in India, according to Medical Council second year teaching has been reduced to one year instead of one and a half year, time constraint would be a major limitation in implementing FCT in routine teaching programme. So, FCT is a method that promotes active engagement and learning of the students. It promotes their mastery over the subject and topic. Evaluating the effectiveness is very important to know the use and impact of this novel teaching approach.

\section{Conclusion}

There was a positive feedback by the students towards flipped teaching method as 
understanding of the topics covered was much more. Similar feedback obtained from the teachers as well though time constraint is an associated issue. But as far as assessment is considered flipped approach offered no additional benefits as compared to non-flipped traditional learning method. In conclusion, flipped model of teaching is feasible in our setting despite the fact that many students had no such experience in the past. In fact, the majority of the students wanted, this method to be continued as active learning is involved.

\section{Acknowledgements}

I acknowledge the help of Second year Students who participated in the project enthusiastically. I acknowledge the help extended by the Department of Microbiology. I acknowledge the help by Dr. Tania, PIMS, Jalandhar and Dr. Nidhi Singla, GMCH, Chandigarh.

\section{References}

Bergmann, J. \& Sams, A. (2012) Flip your classroom: Reach every student in every class every day, International Society for Technology in Education

Brame, C.J. (2013) Flipping the classroom Retrieved, August, 29, p. 2013

Critz, C.M. \& Knight, D. (2013) Using the flipped classroom in graduate nursing education, Nurse educator, 38, 5, pp. 210-213

Deslauriers, L. \& Weiman, C. (2011) Learning and retention of quantum concepts with different teaching methods, Physical review special topics-physics education research, 7, 1, p. 010101

Evans, K.H., Thompson, A.C., O’brien, C., Bryant, M., Basaviah, P., Prober, C. \& Popat, R.A. (2016) An innovative blended preclinical curriculum in clinical epidemiology and biostatistics: impact on student satisfaction and performance, Academic Medicine, 91, 5, pp. 696-700

Hamdan, N., Mcknight, P., Mcknight, K. \& Arfstrom, K.M. (2013) The flipped learning model: A white paper based on the literature review titled a review of flipped learning, Flipped Learning Network, Pearson/George Mason University.

Herbert, C., Velan, G.M., Pryor, W.M. \& Kumar, R.K. (2017) A model for the use of blended learning in large group teaching sessions, BMC medical education, 17, 1, pp. 197
Jensen, J.L., Kummer, T.A. \& Godoy, P.D.D.M. (2015) Improvements from a flipped classroom may simply be the fruits of active learning, CBELife Sciences Education, 14, 1, p. 5

Kashyap, S. (2015) Item analysis of multiple choice questions, International Journal of Current Research, 7, 12, pp. 24057-24058

Lage, M.J., Platt, G.J. \& Treglia, M. (2000) Inverting the classroom: A gateway to creating an inclusive learning environment, The Journal of Economic Education, 31, 1, pp. 30-43.

Lew, E.K. (2016) Creating a contemporary clerkship curriculum: the flipped classroom model in emergency medicine, International journal of emergency medicine, 9,1, p. 25

Martin, S.K., Farnan, J.M. \& Arora, V.M. (2013) Future: new strategies for hospitalists to overcome challenges in teaching on today's wards, Journal of hospital medicine, 8, 7, pp. 409-413

McLaughlin, J.E., Roth, M.T., Glatt, D.M., Gharkholonarehe, N., Davidson, C.A., Griffin, L.M., Esserman, D.A. \& Mumper, R.J. (2014) The flipped classroom: a course redesign to foster learning and engagement in a health professions school, Academic medicine, 89, 2, pp. 236-243

Michaud-sacks, M.C., Feinberg, D. \& Teng, Y. (2014) Promoting active learning with problembased learning (PBL) in a flipped classroom format for pharmacy jurisprudence, 115th Annual Meeting of the American Associaton of Colleges of Pharmacy, Grapevine, American journal of pharmaceutical education, 78, 5, p. 111.

Missildine, K., Fountain, R., Summers, L. \& Gosselin, K. (2013) Flipping the classroom to improve student performance and satisfaction, Journal of Nursing Education, 52, 10, pp. 597-599

Pickering, J.D. \& Roberts, D.J.H. (2018) Flipped classroom or an active lecture? Clinical Anatomy, 31, 1, pp. 118-121

Persky, A.M. \& Dupuis, R.E. (2014) An eight-year retrospective study in "flipped" pharmacokinetics courses, American journal of pharmaceutical education, 78, 10, p. 190

Prober, C.G. \& Heath, C. (2012) Lecture halls without lectures-a proposal for medical education, The New England Journal of Medicine, 366, 18, pp. 1657-1659.

Ratta, C.B. (2015) Flipping the classroom with teambased learning in undergraduate nursing education, Nurse Educator, 40, 2, pp. 71-74 
Schlairet, M.C., Green, R. \& Benton, M.J. (2014) The flipped classroom: strategies for an undergraduate nursing course, Nurse educator, 39, 6, pp. 321-325

Strayer, J.F. (2012) How learning in an inverted classroom influences cooperation, innovation and task orientation Learning environments research, 15, 2, pp. 171-193
Singh, K., Mahajan, R., Gupta, P. \& Singh, T. (2018) Flipped Classroom: A Concept for engaging Medical Students in Learning, Indian Pediatrics, 55,6 , pp. $507-512$

Wong, T.H., Pharm, D., Eric, J.Ip. \& Rajagopalan, V. (2014) Pharmacy students' performance and perceptions in a flipped teaching pilot on cardiac arrhythmias, American journal pharmaceutical education, 78, 10, p. 185 